\title{
"Não tem essas pessoas especiais na minha área": saúde e invisibilidade das populações LGBT na perspectiva de agentes comunitários de saúde
}

\author{
"There are no such special people in my field of working": health and \\ invisibility of LGBT people from the perspective of community health agents \\ "No hay esas personas especiales en mi trabajo": salud e invisibilidad de \\ la población LGBT en la perspectiva de los agentes comunitarios de salud
}

Breno de Oliveira Ferreira ${ }^{1, a}$

breno.oli@hotmail.com | https://orcid.org/o000-0002-0979-3911

Edson Oliveira Pereira ${ }^{2, b}$

edson123@hotmail.com | https://orcid.org/o000-0002-8933-8141

Matheus Barbosa da Rocha ${ }^{3, c}$

matheusbr.psico@live.com | https://orcid.org/o0oo-0003-2483-1100

Elaine Ferreira do Nascimento ${ }^{1, d}$

negraelaine@gmail.com | https://orcid.org/oooo-0001-6839-4323

Ana Rayonara de Sousa Albuquerque ${ }^{4, e}$

anarayif@gmail.com | https://orcid.org/o0oo-0002-9096-350X

Maysa Milena e Silva Almeira ${ }^{5 f}$

maysa123@gmail.com | https://orcid.org/oooo-0002-1632-9148

José Ivo dos Santos Pedrosa $a^{3,9}$

jivopedrosa@gmail.com | https://orcid.org/0000-0002-5416-2860

\footnotetext{
${ }^{1}$ Fundação Oswaldo Cruz. Rio de Janeiro, RJ, Brasil.

2 Universidade de Brasília. Brasília, DF, Brasil.

${ }^{3}$ Universidade Federal do Piauí. Teresina, PI, Brasil.

${ }^{4}$ Instituto Federal de Educação do Maranhão. São Luís, MA, Brasil.

${ }^{5}$ Universidade Federal do Maranhão. São Luís, MA, Brasil.

a Mestrado em Ciências e Saúde pela Universidade Federal do Piauí.

- Mestrado em Saúde Coletiva pela Universidade de Brasília.

c Mestrado em Psicologia pela Universidade Federal do Piauí.

d Doutorado em Saúde Coletiva pela Fundação Oswaldo Cruz.

e Especialização em Fisiologia do Exercício pelo Centro Unificado de Teresina.

f Mestrado em Psicologia pela Universidade Federal do Maranhão.

${ }^{9}$ Doutorado em Saúde Coletiva pela Universidade Estadual de Campinas.
} 


\section{Resumo}

O objetivo do estudo aqui apresentado foi analisar os sentidos atribuídos por agentes comunitários de saúde acerca do cuidado em saúde para as populações LGBT. O método baseia-se numa abordagem de pesquisa qualitativa, por meio de entrevistas semiestruturadas com quinze agentes comunitários de saúde da Estratégia Saúde da Família de uma capital no Nordeste brasileiro. Os dados foram analisados a partir do método de interpretação de sentidos. Entre os principais resultados, destacaram-se dois grandes blocos: (i) demandas de saúde das populações LGBT; e (ii) atuação profissional junto às populações LGBT. A saúde das populações LGBT, especialmente na atenção básica, é uma complexa questão que não tem recebido a devida atenção por parte da formação, gestão e da atenção em saúde como um todo. Dessa forma, a atuação problematizadora desse trabalho coletou relatos, identificou problemas e questões e, consequentemente, por intermédio das percepções dos agentes comunitários de saúde, identificou as violências, negações e discriminações que vivenciam parcelas das populações LGBT nas unidades de saúde, espaços que deveriam oferecer cuidado equânime e integral.

Palavras-chave: Identidade de gênero; Orientação sexual; Agentes comunitários de saúde; Sistema Único de Saúde (SUS); Assistência integral à saúde.

\section{Abstract}

The objective of the study presented here was to analyze the meanings attributed by community health agents regarding health care to LGBT population. The method is based on a qualitative research approach, through semi-structured interviews with 15 community health agents of the Estratégia Saúde da Família (Family Health Strategy, a Brazilian health programme) of a city of the Northeast Region of Brazil. The data were analyzed using the meaning interpretation method. Among the main results, two stand out: (i) LGBT population health claims; and (ii) Professional performance in regard to LGBT population. The health of LGBT population, especially in primary care, is a complex issue which hasn't received the proper attention by care formation, management and health attention as a whole. Thus, with the purpose of identifying the origins of that issue this work collected reports, detected problems and related issues and, consequently, by means of perceptions of the community health agents discovered the violences, denials and discriminations that some LGBT experience in health units, spaces who should provide impartial and comprehensive care.

Keywords: Gender identity; Sexual orientation; Community health agents; SUS - Sistema Único de Saúde (Unified Health System); Comprehensive health care.

\section{Resumen}

El objetivo del estudio aquí presentado fue analizar los sentidos atribuidos por agentes comunitarios de salud acerca del cuidado en salud a la población LGBT. El método se basa en un enfoque de investigación cualitativa, a través de entrevistas semiestructuradas con 15 agentes comunitarios de salud de la Estratégia Saúde da Família (Estrategia Salud de la Familia, programa brasileño de salud) de una ciudad de la Región Nordeste de Brasil. Los datos fueron analizados a partir del método de interpretación de sentidos. Entre los principales resultados, se destacaron dos: (i) Demandas de salud de la población LGBT; y (ii) Actuación profesional ante la población LGBT. La salud de la población LGBT, especialmente en la atención primaria de salud, es una compleja cuestión que no ha estado recibiendo la debida atención por parte de la formación, gestión y atención en salud como un todo. Así que la actuación problematizadora de este trabajo ha reunido relatos, identificado problemas y cuestiones y, consecuentemente, por medio de la percepción de los agentes comunitarios de salud, ha descubiertolas violencias, negaciones y discriminaciones que vivencian algunas personas LGBT en las unidades de salud, espacios que deberián ofrecer cuidado ecuánime e integral.

Palabras clave: Identidad de género; Orientación sexual; Agentes comunitarios de salud; SUS - Sistema Único de Saúde (Sistema Único de Salud); Atención integral de salud. 
Este artigo faz parte do dossiê $\mathbf{4 0}$ anos do movimento LGBT: visibilidades e representações.

Contribuição dos autores: Todos os autores participaram de todas as etapas do texto.

Declaração de conflito de interesses: não houve.

Fontes de financiamento: não houve.

Considerações éticas: a presente investigação recebeu aprovação do Comitê de Ética em Pesquisa da Faculdade de Ciências da Saúde da Universidade de Brasília, sob Parecer no 652.643, de acordo com a Resolução 466/2012 e a 510/2016 do Conselho Nacional de Saúde.

Agradecimentos/Contribuições adicionais: não há.

Histórico do artigo: submetido: 31 jan. 2018 | aceito: 17 jul. 2019 | publicado: 12 set. 2019.

Apresentação anterior: não houve.

Licença CC BY-NC atribuição não comercial. Com essa licença é permitido acessar, baixar (download), copiar, imprimir, compartilhar, reutilizar e distribuir os artigos, desde que para uso não comercial e com a citação da fonte, conferindo os devidos créditos de autoria e menção à Reciis. Nesses casos, nenhuma permissão é necessária por parte dos autores ou dos editores.

\section{Introdução}

Ao analisarmos a genealogia das questões de gênero e sexualidade daqueles que escapam ao binarismo sexual, especialmente referentes às populações de lésbicas, gays, bissexuais, travestis e transexuais (LGBT), percebemos que, ao longo dos tempos, não tiveram um lugar na 'história oficial' da humanidade, a não ser como atores secundários que desviavam, distorciam ou mesmo maculavam a memória dos povos, heterossexualmente orientada. Assim, esses sujeitos construíram memórias 'marginais', silenciosas, desejosas de se fazerem visíveis e parte legítima da sociedade ${ }^{1}$.

Nesse aspecto, constata-se que os elementos presentes nos contextos social, cultural, econômico e político do Brasil enredaram processos de invisibilidade e vulnerabilidades nos diferentes aspectos de vida para as populações LGBT. São sujeitos que frequentemente vivenciam barreiras no acesso às oportunidades de emprego, discriminação no ambiente da família, do trabalho, da educação e em especial, da saúde. Quando aliadas aos marcadores de gênero, raça/cor e classe, engendram questões ainda mais problemáticas.

Durante o governo do presidente Luís Inácio Lula da Silva (2003-2011) e, posteriormente, de Dilma Roussef (2011-2016), houve um maior reconhecimento da diversidade sexual e de gênero nas pautas das políticas públicas, processo esse perceptível principalmente devido à criação de secretarias relacionadas aos direitos humanos, às mulheres, à igualdade racial e à juventude, conquistadas graças aos processos de negociações, pactuações e representatividades de diversos atores políticos, entre eles as populações LGBT3

Dentro do campo interdisciplinar da saúde, o conceito de vulnerabilidade tem sido dialogado com e a partir do processo de determinação social, compreendendo as chances de risco aumentadas pela exposição das pessoas frente aos cenários de doença, que podem ser individuais e coletivos, e, contudo, como uma questão social, de proteção à vida. Adotaremos, portanto, a vulnerabilidade como um processo dinâmico e crítico que deve se atualizar nas relações sociais permanentemente e que deve estar na pauta das lutas políticas da saúde coletiva e dos movimentos sociais. Para as populações LGBT, a tríade saúde-adoecimento-cuidado tem gerado especificidades e fragilidades no contexto dos serviços de saúde, deixando-as ainda mais vulneráveis4 ${ }^{4}$

Depois de muitas lutas e disputas de agenda provocadas pelos movimentos LGBT, ao apagar das luzes do ano de 2011, a Política Nacional de Saúde Integral da População LGBT (Portaria no 2.836) foi publicada 
como uma resposta às inúmeras demandas emudecidas dessa população, pautando-se principalmente nos princípios doutrinários do Sistema Único de Saúde (SUS) e da justiça social, reconhecendo que a orientação sexual e a identidade de gênero não normativa são condicionantes de saúde ${ }^{5}$.

Deacordo com a política, as intervenções a serem desenvolvidas englobam ações intersetoriais de educação permanente e continuada em direitos humanos no SUS; a inclusão de questões relacionadas à identidade de gênero e orientação sexual nos formulários e prontuários do sistema; participação dos movimentos sociais LGBT nos conselhos de saúde; garantia dos direitos sexuais e reprodutivos; estabelecimento de normas e procedimentos para atendimento humanizado; aprimoramento do processo transexualizador; e ações de prevenção contra as IST/aids ${ }^{6}$.

Um dos cenários em que esse marco legal pode ser institucionalizado diz respeito à atenção básica em saúde, mais especificamente na Estratégia Saúde da Família (ESF). De modo geral, suas equipes são compostas por médico, enfermeiro, técnico ou auxiliar de enfermagem, cirurgião-dentista, técnico ou auxiliar em saúde bucal e os agentes comunitários de saúde (ACS) ${ }^{6}$. Ao ACS é incumbida a responsabilidade de atuar como um elo entre a comunidade e o próprio sistema de saúde. Também é função desse profissional realizar atividades de prevenção de doenças e promoção da saúde, por meio de ações coletivas ou individuais, além de ter acesso aos domicílios e, consequentemente, ao cotidiano das famílias ${ }^{8,9}$. Mas de que família estamos falando quando nossas lentes se aproximam da realidade das populações LGBT? Em um terreno de normatividades e assimetrias de gênero, em que o modelo de família nuclear e tradicional é o centro do cuidado em saúde, como são acolhidas as populações LGBT nas unidades de saúde?

Diante de tais questões e o que a literatura tem nos mostrado ${ }^{2,4,7}$, percebemos ser necessário não somente o ACS, como também todos os profissionais que atuam na atenção básica, agregarem em seu cotidiano de trabalho ações inclusivas e de respeito às populações LGBT. Por conta disso, o presente artigo teve como objetivo analisar os sentidos atribuídos por quinze agentes comunitários de saúde, que atuam em uma capital do nordeste do Brasil, acerca do cuidado às populações LGBT, tais como acesso aos serviços de saúde, estigma, discriminação e preconceito durante os atendimentos, formação profissional para atuar com a diversidade sexual e de gênero e articulação com os diferentes equipamentos sociais da rede de atenção à saúde.

\section{Métodos}

Trata-se de um estudo de natureza qualitativa, desenvolvido em uma capital do nordeste brasileiro que, atualmente, possui uma cobertura da Estratégia Saúde da Família em todos os bairros, o que representa uma cobertura total da população. A capital possui noventa unidades básicas de saúde (UBS) distribuídas nas áreas urbana e rural. Paradoxalmente, ocupa posições preocupantes no que se refere aos altos índices de violências contra as populações LGBT, de acordo com os relatórios anuais do Grupo Gay da Bahia (GGB) .

Nesse percurso metodológico, foram listadas as unidades de cada território da cidade (Centro-Norte, Leste-Sudeste e Sul) que possuíam equipes funcionando com cadastro atualizado no Sistema de Cadastro Nacional de Estabelecimentos de Saúde (SCNES), e que foram sorteadas por território pelos pesquisadores, que localizaram, assim, os quinze informantes (agentes comunitários de saúde), incluídos por atuarem havia pelo menos um ano no território de saúde. Também foi critério de inclusão não pertencer à mesma equipe de outro profissional já incluído no estudo. O critério de exclusão adotado foi o cancelamento ou a impossibilidade, após três tentativas, de compatibilizar horário para agendamento da entrevista, bem como aqueles afastados por licenças e/ou tratamentos de saúde.

As informações foram coletadas por meio de entrevistas semiestruturadas e analisadas a partir do método de interpretação de sentidos. Esse método baseia-se em princípios hermenêutico-dialéticos que buscam interpretar o contexto, as razões e as lógicas de falas. Na trajetória analítico-interpretativa dos textos foram percorridos os seguintes passos: (i) leitura compreensiva, com vistas ao desenvolvimento, à visão de conjunto e à apreensão das 
particularidades do material da pesquisa; (ii) identificação e recorte temático que emergiram das entrevistas; (iii) identificação e problematização das ideias explícitas e implícitas nos discursos; (iv) busca de sentidos mais amplos (socioculturais), subjacentes às falas dos sujeitos da pesquisa; (v) diálogo entre as ideias problematizadas, informações provenientes de outros estudos acerca do assunto e o referencial teórico do estudo; e (vi) elaboração de síntese interpretativa, procurando articular objetivo do estudo, base teórica adotada e dados empíricos ${ }^{9}$

Todos os participantes assinaram o Termo de Consentimento Livre e Esclarecido, e para manter o anonimato, foi acrescido 'ACS', que representa 'agente comunitário de saúde', e um número arábico que indica a sequência da entrevista realizada: (ACS 1), (ACS 2), (ACS 3), e assim por diante.

A presente produção também esteve relacionada à pesquisa nacional, do Ministério da Saúde, intitulada 'Análise do acesso e da qualidade da atenção integral à saúde da população LGBT no SUS', coordenada pelo Núcleo de Estudos em Saúde Pública da Universidade de Brasília (Nesp/UnB), em parceria com várias universidades ${ }^{10}$.

\section{Resultados e discussões}

As entrevistas com os agentes comunitários de saúde sobre a atenção integral à saúde das populações LGBT possibilitaram a emergência de dois grandes eixos de análise: 3.1 Demandas de saúde das populações LGBT; 3.2 Atuação profissional junto às populações LGBT, tendo sido esse último subdividido em outros cinco subtópicos: 3.2.1 Acesso ao Sistema Único de Saúde pelas populações LGBT; 3.2.2 Atividades destinadas às populações LGBT; 3.2.3 Implantação e institucionalização da Política Nacional de Atenção Integral à Saúde das Populações LGBT; 3.2.4 Integração entre a ESF e os demais pontos da rede de apoio às populações LGBT; e 3.2.5 Formação para trabalhar com as populações LGBT.

\section{Demandas de saúde das populações LGBT}

No que se refere às demandas de saúde das populações LGBT, os discursos dos agentes comunitários de saúde fizeram referência a quatro perspectivas: a) desconhecimento das demandas em saúde das populações LGBT; b) estigma e preconceito na assistência à saúde das populações LGBT; c) premissa generalista, em que todos os sujeitos, apesar das diferenças históricas, sociais, econômicas, políticas e culturais que lhe atravessam, são tratados como seres semelhantes; d) compreensão ampliada às demandas de saúde das populações LGBT.

A primeira perspectiva está organizada do seguinte modo: enquanto alguns dos profissionais entrevistados (1 e 10) afirmam que, em suas respectivas áreas de abrangência, não existem pessoas LGBT, outros (7, 8 e 9) destacaram não saber quais demandas em saúde são específicas dessas populações em estudo.

Quadro 1-Desconhecimento das demandas em saúde das populações LGBT

\begin{tabular}{|l|l|}
\hline ACS 1 & Na minha microárea, eu não posso falar porque [ela] não tem essas pessoas especiais. \\
\hline ACS 7 & $\begin{array}{l}\text { Não, não tenho conhecimento, não sei nem se ela existe, uma relação [de saúde] separada para esse } \\
\text { grupo específico. Creio que não. }\end{array}$ \\
\hline ACS 8 & $\begin{array}{l}\text { Esse assunto, com toda a sinceridade, é a primeira vez que eu estou ouvindo falar. Se aparece algum } \\
\text { gay ou lésbica sendo consultado pelo médico eu já não sei como funciona. }\end{array}$ \\
\hline ACS 9 & $\begin{array}{l}\text { Eu nem sei, porque nas áreas [em] que eu já trabalhei quase a gente não identifica ou eles não se } \\
\text { identificam que são [...] }\end{array}$ \\
\hline ACS 10 & Na minha área, eu não tenho casos de lésbicas, nem de bissexuais e nem de gays, é pouco. \\
\hline
\end{tabular}

Fonte: Elaborado pelos autores (2019).

No segundo grupo de significação dos discursos dos agentes comunitários de saúde (2, 4, 6, 8, 11 e 15) sobre as demandas em saúde das populações LGBT, conseguimos identificar compreensões que, na maioria das vezes, 
se aproximavam mais do senso comum do que das perspectivas ético-políticas que norteiam o SUS e o fazer dos profissionais da saúde. Nesse sentido, o que pudemos observar foram relatos que ou associavam essas populações como um possível grupo de risco para o aparecimento de IST/aids (premissa bastante reverberada durante os anos 1980 e 1990), conforme aponta a literatura mundial ${ }^{11}$, ou a partir de outras visões patologizantes.

Quadro 2 - Estigma e preconceito na assistência à saúde das populações LGBT

\begin{tabular}{|l|l|}
\hline ACS 2 & No caso, mais assim a questão de prevenção de DST. Eles se preocupam muito. \\
\hline ACS 4 & $\begin{array}{l}\text { Assim, quando acontece... já teve um, inclusive não era da minha área, era de uma área adjacente, } \\
\text { que ele tava com um problema que eu acho que era tipo uma doença venérea, ele falou comigo } \\
\text { particularmente e queria, me perguntou como é que ele ia conseguir um encaminhamento. }\end{array}$ \\
\hline ACS 6 & $\begin{array}{l}\text { É exatamente essa questão de exame para detectar DST. O que a gente mais ouve falar é justamente } \\
\text { essa preocupação em termos de exame, eles perguntam muito pelo exame, como é que faz e tudo } \\
\text { mais, às vezes eles não contam que eles tão querendo fazer. }\end{array}$ \\
\hline ACS 8 & $\begin{array}{l}\text { Eu acho que quando vem é porque já tá sério, mas quando vem é "novim", "pitelzim". Não tem mais } \\
\text { aqueles "véi" antigo, acho que já morreram tudo, tá os "novim" agora. Os "novim" são mais saudável, } \\
\text { só se pegarem doença venérea... }\end{array}$ \\
\hline ACS 11 & $\begin{array}{l}\text { Eles procuram [...] São poucas, como já falei, mas eles procuram muito para fazer exames, e também } \\
\text { para [...] principalmente comigo para pegar camisinha. }\end{array}$ \\
\hline ACS 15 & $\begin{array}{l}\text { Tínhamos alguns casos de HIV, só que é tão difícil a comunicação dos pacientes com o posto que, às } \\
\text { vezes, quando a gente fica sabendo já está em estado terminal. }\end{array}$ \\
\hline
\end{tabular}

Fonte: Elaborado pelos autores (2019).

A terceira perspectiva sobre as demandas de saúde das populações LGBT presente nos discursos dos participantes (1, 3, 4, 7 e 15) traz consigo, indiretamente, a ideia de que esse grupo não teria qualquer espécie de singularidade social, histórica, econômica, política e cultural que devesse ser levada em consideração no trabalho em saúde, já que aparentemente todos viveriam e adoeceriam do mesmo modo, não havendo, portanto, uma justificativa sólida para destinar ações a essas populações em específico.

Quadro 3 - Perspectiva generalista em torno das demandas em saúde das populações LGBT

\begin{tabular}{|l|l|}
\hline ACS 1 & Isto depende do grau de instrução de cada um. Porque, quando ele tem instrução, ele se cuida mais. \\
\hline ACS 3 & Consulta médica mesmo. Nada específico. \\
\hline ACS 4 & É como o restante da população, quando eles apresentam uma febre, uma dor, viu. \\
\hline ACS 7 & É exames, é... fazer checkup de rotina. \\
\hline ACS 15 & $\begin{array}{l}\text { A maioria tem orientação [de saúde] igual ao heterossexual, só que existe o lado ruim dos dois casos, } \\
\text { tanto no lado heterossexual como no lado dos transexuais, gays, homossexuais, porque boa parte da } \\
\text { população não se previne, não vai ao médico periodicamente, não faz exame de rotina. }\end{array}$ \\
\hline
\end{tabular}

Fonte: Elaborado pelos autores (2019).

Por fim, também nos deparamos com discursos ( $\operatorname{ACS}$ 1, 2, 9, 12 e 13) que compreendiam as demandas em saúde das populações LGBT para além de perspectivas biomédicas e patologizantes, fazendo referência aos determinantes sociais da saúde, a luta pela igualdade de gênero, o aparecimento de questões de ordem psicológica em decorrência dos constantes casos de preconceito e violência que eles e elas costumam vivenciar, o constrangimento de compartilhar vivências referentes à sociabilidade sexual com os profissionais de saúde, entre outras implicações. 
Quadro 4-Compreensão ampliada das demandas de saúde das populações LGBT

\begin{tabular}{|l|l|}
\hline ACS 1 & A reclamação é sempre pela igualdade. \\
\hline ACS $\mathbf{2}$ & $\begin{array}{l}\text { Muitas vezes, tem a questão da vergonha. Se ela quer marcar uma consulta, uma prevenção, ela fica } \\
\text { com aquele receio de falar alguma coisa. Âs vezes, com medo de falar alguma coisa. }\end{array}$ \\
\hline ACS $\mathbf{9}$ & $\begin{array}{l}\text { Todo mundo tem um problema. Acredito que eles tenham muitos problemas, principalmente depressão. } \\
\text { Como eles se sentem com relação ao que as pessoas acham deles. Daí eles devem ter tratamento com } \\
\text { psicólogos. Na verdade, eu acho que são vários serviços que eles precisam, não só com relação às } \\
\text { doenças, mas com o psicológico deles. }\end{array}$ \\
\hline ACS 12 & $\begin{array}{l}\text { Eles se prendem muito. Às vezes, até existem na área, mas muitas vezes eles se prendem por causa } \\
\text { da questão do preconceito, não falam que são..., e aí vêm como pessoas que não são dessa classe. }\end{array}$ \\
\hline ACS 13 & $\begin{array}{l}\text { É uma demanda que não chega tanto, apesar da política estar aí, de terem muitos direitos. Mas acredito } \\
\text { que essas pessoas, por conta da discriminação e do preconceito ainda estão escondidas, é um grupo } \\
\text { que muitas vezes fica escondido, não busca o serviço de saúde. }\end{array}$ \\
\hline
\end{tabular}

Fonte: Elaborado pelos autores (2019).

De acordo com alguns estudos ${ }^{7,12}$, as negações, violências, negligências e invisibilidades das populações LGBT nos serviços de saúde se ancoram numa perspectiva estrutural, econômica, simbólica e política da sociedade como um todo. A falta de reconhecimento dessas populações dissidentes se sustenta e é retroalimentada por uma perspectiva fundamentada no patriarcalismo, no machismo e no sexismo que vem imperando em todas as relações sociais, inclusive dentro das instituições de saúde. Outra perspectiva narrada é a responsabilização dos processos que envolvem situações de preconceito como se originassem das/nas próprias populações LGBT. Há uma culpabilização ou a imposição de um sistema sexo-gênero que reconhece apenas os sujeitos normativos, devolvendo àqueles que desconstroem o binarismo sexual um lugar de valência negativa e dolosa. Os estudos apontam que existem obstáculos subjetivos e também concretos que interferem no acesso e na qualidade da assistência à saúde das populações LGBT às unidades de saúde. E quem são os ACS nesse movimento de violências em cascatas?

Os ACS são profissionais que, em tese, devem conhecer profundamente a realidade local em que estão inseridos, identificando as crenças, os rituais, as linguagens, os grupos e as nuances do território a que foram adscritos. Representam uma possibilidade estratégica de compartilhar com as equipes de saúde as questões que atravessam esse campo. Através de suas lentes são capazes de revelar as necessidades de saúde de um ponto de vista diferente e que, portanto, pode abrir espaços para um universo novo no processo de trabalho ${ }^{13}$. Não obstante, as falas têm mostrado que os ACS são profissionais que não se envolvem com os processos de cuidado às populações LGBT, que trazem concepções ainda tradicionais e normativas para a assistência à saúde. Se esses profissionais que estão mais perto da comunidade pensam nessa lógica, como podem as populações LGBT acessar os demais profissionais das unidades de saúde?

Notou-se também a redução das necessidades das populações LGBT relativas às IST/aids, não corroborando os achados da literatura nacional e internacional ${ }^{11}$, em que essas populações são ainda vistas como produtoras de 'doenças venéreas' ou 'infectantes', e para alguns participantes é o que legitimaria a sua procura dos serviços de saúde. Os dados estatísticos da Unaids são chaves importantes para entender essa quase centralidade da temática de HIV/aids associada às populações LGBT e aos estigmas produzidos. Embora se tenham alcançado avanços nos mais diferentes aspectos, 36,9 milhões de pessoas em todo o mundo viviam com HIV em 2017, entre elas, gays e pessoas trans, que são grupos historicamente marginalizados pela epidemia. $\mathrm{O}$ risco de infecção pelo HIV é 27 vezes maior entre os gays e 13 vezes maior entre mulheres trans. Um estudo recente ${ }^{14}$ mostrou que esses dados atravessam a análise do estigma a partir de lentes morais, éticas, organizacionais e políticas no campo da saúde, além de ser um debate imprescindível para a atenção básica. 
Mesmo reconhecendo o uso do termo homofobia no mundo, atualmente existe uma tendência a usar os termos lesbofobia para as mulheres lésbicas, bifobia para bissexuais, transfobia para as pessoas trans, e incluindo todos os ingredientes da 'sopa de letrinhas', LGBTfobia. O estigma imbricado com as discriminações, preconceitos e violências contra as populações LGBT são pautas fundamentais para as lutas, negociações e disputas nas diferentes agendas políticas. Para a saúde, são fatores que interferem na dinâmica da determinação social e podem gerar outros adoecimentos ${ }^{15}$.

\section{Atuação profissional junto às populações LGBT}

\section{Acesso ao Sistema Único de Saúde pelas populações LGBT}

De acordo com os profissionais entrevistados, o acesso das populações LGBT aos serviços oferecidos pelas equipes Saúde da Família a que os mesmos estavam vinculados está configurado a partir de dois pressupostos: a) não há nenhuma espécie de dificuldade desse público acessar o serviço, já que todos os usuários são tratados igualmente; e b) a heteronormatividade ainda dificulta a oferta e o acesso de tais sujeitos ao direito básico da saúde.

No primeiro pressuposto, há o entendimento de que todos os usuários são tratados indistintamente, sem quaisquer formas de discriminação ou preconceito, de modo que, na compreensão dos respectivos profissionais $(3,4,5,6,7,8,10,12,14)$, não há dificuldades das populações LGBT acessarem os serviços, já que as mesmas supostamente seriam sempre bem atendidas.

\section{Quadro 5-Ausência de dificuldade das populações LGBT acessarem o SUS}

\begin{tabular}{|c|c|}
\hline ACS 3 & $\begin{array}{l}\text { Eles chegam e são bem atendidos e querem voltar de novo. Tem duas ou três unidades aqui próximas, } \\
\text { fazem questão de ficar aqui e não querem ir para lá. }\end{array}$ \\
\hline ACS 4 & $\begin{array}{l}\text { Eu acho que o próprio funcionário já tem uma atenção particular, porque ele pode se sentir até mesmo } \\
\text { assim, por exemplo, não, se eu não tratar ele bem ele pode até me denunciar, entendeu? Assim, tipo } \\
\text { ele já sabe que a população, ela tem leis, sabe? }\end{array}$ \\
\hline ACS 5 & $\begin{array}{l}\text { Nunca vi caso aqui de relação de segregação ou de discriminação, até que não pode, então quer dizer } \\
\text { que as mesmas coisas e problemas que são para o público normal, são para o LGBT. }\end{array}$ \\
\hline ACS 6 & Em termos de oferta de serviços eu creio que não, eu não vejo, assim, dificuldades. \\
\hline ACS 7 & $\begin{array}{l}\text { Não, nenhuma dificuldade, ou melhor, eles têm a mesma dificuldade que qualquer pessoa tem, tipo } \\
\text { assim, questão de conseguir um médico especialista para alguma área que estão precisando, isso eles } \\
\text { têm como qualquer pessoa. }\end{array}$ \\
\hline ACS 8 & $\begin{array}{l}\text { Tem não [dificuldade], eu acho que não. Porque é o básico aqui a saúde, é o básico. Então, chegou } \\
\text { aqui, o médico resolve logo. }\end{array}$ \\
\hline ACS 10 & $\begin{array}{l}\text { Eu acho que o pessoal aqui é bem acolhedor e eu acho que precisa mais é o agente mesmo orientar } \\
\text { para eles virem, mas aqui é acolhedor, todo mundo é acolhedor aqui. }\end{array}$ \\
\hline ACS 12 & Acho que é questão deles mesmos que não querem vir para o Posto. Acho que não tem essa dificuldade. \\
\hline ACS 14 & Dificuldade no sistema, aqui na Unidade, não. Eu acho que a dificuldade é deles mesmo. \\
\hline
\end{tabular}

Fonte: Elaborado pelos autores (2019).

Apesar dessa compreensão majoritariamente presente entre os participantes, alguns dos profissionais entrevistados $(5,9,10,11,13$ e 15) relataram que as populações LGBT têm dificuldades de acesso aos serviços de saúde, em grande parte por causa do preconceito e da discriminação que essas pessoas constantemente têm sofrido. 
Quadro 6-Dificuldades das populações LGBT de acessar o SUS

\begin{tabular}{|l|l|}
\hline ACS 5 & $\begin{array}{l}\text { Eu acredito que sim [existe dificuldade de acesso aos serviços de saúde], principalmente em relação até } \\
\text { ao próprio preconceito que aqui tem [...]. Eu vejo na parte de atendimento do posto, ou talvez porque } \\
\text { a pessoa também tenha vergonha de vir, de se expor. }\end{array}$ \\
\hline ACS 9 & $\begin{array}{l}\text { A gente vê que eles não frequentam muito a nossa Unidade de Saúde, não sei qual o motivo. Talvez } \\
\text { com medo do preconceito. }\end{array}$ \\
\hline ACS 10 10 & $\begin{array}{l}\text { É muita hipocrisia dizer que não tem preconceito, porque tem. Geralmente quase todos têm. E eles } \\
\text { também ficam com receio. Eu não posso nem dizer pela equipe, porque a gente quase não tem, e eu } \\
\text { acredito que falta divulgação. Eu acho que tem um pouco de preconceito. }\end{array}$ \\
\hline ACS 11 & $\begin{array}{l}\text { O LGBT tem dificuldade de vir até o posto. Acho que porque ele por si só que tem preconceito. Eles são } \\
\text { pessoas muito difíceis até da gente encontrar em casa [...]. Inclusive com o ACS eles têm medo. Eu não. } \\
\text { Eu já disse, eu tenho vários meninos gays e que eles me procuram porque eles têm confiança em mim } \\
\text { e eu levo até a doutora. Mas eles são muito difíceis de procurar. Eles preferem ficar trancados dentro } \\
\text { de uma casa, ou então trancados para si mesmo. }\end{array}$ \\
\hline ACS 13 & $\begin{array}{l}\text { Com certeza [os LGBT têm dificuldade de acessar os serviços de saúde]. Como eu já disse, principalmente } \\
\text { pelo preconceito, pela falta de condições, muitas vezes dos profissionais que estão no serviço e do } \\
\text { próprio serviço de forma geral. }\end{array}$ \\
\hline ACS 15 & $\begin{array}{l}\text { Não acredito que eles tenham dificuldade de acesso à saúde. Acho que é mais o medo de se expor, é o } \\
\text { medo de discriminação mesmo. }\end{array}$ \\
\hline
\end{tabular}

Fonte: Elaborado pelos autores (2019).

Durante as entrevistas realizadas, os agentes comunitários de saúde afirmaram que, quando as populações LGBT precisam acessar os serviços oferecidos pelas equipes Saúde da Família, este contato acontece a partir das seguintes configurações: (i) estes sujeitos só frequentam a unidade de saúde quando necessitam de algum procedimento médico (ACS 4); (ii) os ACS são os profissionais que têm o primeiro contato com essas populações (ACS 3); (iii) os ACS costumam marcar consultas de porta em porta, para que os mesmos não se sintam constrangidos na unidade (ACS 1); (iv) a equipe de saúde procura dias e horários com pouca movimentação para que as populações LGBT possam ser atendidas sem constrangimentos (ACS 15); e (v) comparecem normalmente assim como qualquer outra pessoa, já que é a partir da atenção básica que se tem acesso às consultas especializadas (ACS 4).

Uma pesquisa descritiva abordando ações fornecidas às mulheres lésbicas em consultórios de ginecologia apontou que 59,5\% das informantes revelaram sua orientação sexual ao profissional de saúde, sendo que, destas, $88,6 \%$ por iniciativa própria e 5,1\% após questionamento pelo profissional. Por fim, a pesquisa concluiu que 18,3\% perceberam uma reação discriminatória do profissional após a revelação, e, entre as mulheres que não revelaram sua orientação, 30,6\% saíram da sala com receituário referente a algum tipo de método contraceptivo, $19,4 \%$ com indicação de preservativo masculino, 3,2\% com indicação de teste de gravidez e 4,8\% com hipótese diagnóstica de gravidez ${ }^{16}$.

As evidências são claras para a invisibilidade do lugar das populações LGBT nos serviços de saúde, em face dos modelos que de maneira implícita ou explícita são reproduzidos pelos agentes comunitários, que, em sua maioria, parecem estar preparados para assistir os sujeitos normativos, heterossexuais, adultos, casados e trabalhadores formais. Por fim, as suas práticas profissionais de cuidado não podem ser vistas apenas como competências técnicas, plasmadas pela burocracia dos serviços, mas, pelo contrário, deveriam ser concebidas como acolhimento, formação de vínculos, subjetividades, escuta, e mediante o uso de diversas outras tecnologias leves que estejam presentes nas valises desses profissionais. 


\section{Atividades destinadas às populações LGBT}

No que se refere à promoção de atividades destinadas às populações LGBT, a maioria dos profissionais entrevistados (1, 2, 3, 4, 5, 7, 12, 14 e 15) afirmou que todos os usuários cobertos pelas respectivas equipes Saúde da Família são atendidos indistintamente, não havendo qualquer espécie de preconceito ou discriminação na oferta das atividades ou mesmo ações específicas a essas populações.

Quando questionados de modo mais incisivo sobre a existência de atividades específicas destinadas aos LGBT, seis participantes (2, 7, 9, 10, 14 e 15) narraram não desenvolver nenhuma atividade com esse público, já que, segundo os próprios, as equipes em que os mesmos trabalham costumam resguardar a orientação sexual e/ou identidade de gênero dos usuários que atendem.

Outros cinco agentes comunitários de saúde $(5,11,12,13$ e 15) também relataram que as equipes que compunham não desenvolviam ações destinadas às populações LGBT; entretanto, ao contrário dos demais participantes, eles justificaram a ausência de atividades seja pela falta de usuários LGBT na unidade de saúde (ACS 11), seja pela priorização de outros grupos, como os diabéticos (ACS 5), ou ainda pela nãoimplantação de alguma política que seja específica a esse grupo populacional (ACS 12, 13, 15).

Das poucas atividades direcionadas exclusivamente para as populações LGBT, um dos entrevistados (ACS 6) mencionou a presença de uma ficha cadastral recém-implantada na atenção básica, na qual era necessário que os agentes comunitários de saúde abordassem a orientação sexual e a identidade de gênero dos usuários sob suas responsabilidades. Além disso, outro participante mencionou que havia recebido um treinamento para aprender como assistir as pessoas trans, fazendo menção especialmente ao que se refere ao uso do nome social (ACS 5).

Apesar disso, os sujeitos relataram que algumas das intervenções que suas equipes ofereciam poderiam ser direcionadas às populações LGBT, tais como: acolhimento (ACS 6); distribuição de preservativos (ACS 1), de panfletos sobre Infecções Sexualmente Transmissíveis (ACS 8) e de camisinhas durante o período do carnaval (ACS 7); e realização de exames de sangue para detectar Infecções Sexualmente Transmissíveis.

Um dos grandes desafios do SUS é fomentar estratégias de cuidado integral à saúde das populações LGBT. Todavia, as falas dos informantes trouxeram cenas de discriminação, de associação das ações voltadas para as IST/aids às populações LGBT e a quase centralidade disso, bem como pouca visibilidade do seu potencial trabalho inclusivo no território de atuação. Por isso, o SUS almeja a formação de um campo de consciência política, como captadora de agências de ativação de mudanças. A saúde coletiva almejada precisa ser formada por um espaço capaz de perceber ao mesmo tempo a complexidade e a necessidade de um suporte humanístico às populações LGBT ${ }^{1718}$.

\section{Implantação e institucionalização da Política Nacional de Atenção Integral à Saúde das Populações LGBT}

Outro eixo de discussão que emergiu a partir das entrevistas diz respeito à percepção dos agentes comunitários de saúde sobre a implantação e institucionalização da Política Nacional de Atenção Integral à Saúde das Populações LGBT. De modo geral, pudemos identificar cinco tipos de posicionamentos diante desse marco legal: (i) desconhecimento da existência de uma política específica para as populações LGBT (ACS 5, 9 e 12); (ii) falta de maiores informações sobre a política em questão (ACS 2, 4, 6, 7 e 10); (iii) os poucos conhecimentos sobre o assunto provêm da televisão (ACS 2) ou de cartilhas ministeriais (ACS 4); (iv) não há uma implantação do marco legal em questão nas unidades de saúde na qual os agentes comunitários de saúde trabalham (ACS 1, 2, 11, 13 e 18); (v) a ideia de que uma política destinada às populações LGBT seria um desperdício de dinheiro e só serviria para proporcionar mais preconceito entre essas populações (ACS 8, 14 e 15); (vi) a compreensão de que a política é efetiva, já tendo contribuído para o cuidado em saúde a usuários do território em que o profissional atuava (ACS 3).

A partir do elenco de questões levantadas acima podemos perceber não apenas a invisibilidade das populações LGBT, mas um apagamento social e concreto desses sujeitos para os serviços de saúde, o que 
também foi percebido em outra pesquisa realizada com os agentes comunitários de saúde7. Qual cuidado pode ser realizado quando os sujeitos não são percebidos? Parece-nos que nenhum! Existe um desconhecimento generalizado em relação à política e, portanto, a luta pela garantia de direitos à saúde se torna cada vez mais pauta da militância e dos movimentos sociais LGBT. Por outro lado, o conhecimento acerca da política não nos garante que a assistência oferecida às populações LGBT seja equânime e respeitosa.

$\mathrm{Se}$, de um lado, temos profissionais que atuam no território próximo às pessoas em suas diferentes condições de vida, do outro, destacamos que os desafios colocados para o SUS são convergentes com aqueles que permeiam a atenção básica, como as fragilidades de articulação entre as diferentes políticas de saúde, a hegemonia do modelo biomédico, a falta de profissionais qualificados, que, somados à insuficiência dos investimentos na área da saúde e à própria precarização do trabalho, constituem gargalos a serem superados. Destacamos que a falta de prioridade do governo para com o SUS nos últimos três anos e os ataques visando ao seu desmonte foram reforçados pela crise econômica, pelas políticas de austeridade fiscal e, especialmente, pela Emenda Constitucional 95 (EC-95/2016), que congela o orçamento público durante vinte anos ${ }^{19}$. E os desafios relacionados à incorporação dos direitos sexuais no campo de ação da Estratégia Saúde da Família parecem ser potenciados pelos mesmos paradoxos inscritos na dinâmica do próprio SUS ${ }^{20}$.

O tema saúde LGBT, especialmente quando abordado pela atenção básica, tem se tornado uma questão complexa que não tem recebido a devida compreensão por parte de eixos formadores, da gestão ou da atenção em saúde como um todo. Dessa forma, a atuação problematizadora deste trabalho coletou relatos, identificou problemas e questões e, consequentemente, também gerou inquietações para todos aqueles que compõem o campo da saúde.

\section{Integração entre a ESF e os demais pontos da rede de apoio às populações LGBT}

Outros elementos que emergiram durante as entrevistas foram as possibilidades de integração entre as equipes da Estratégia Saúde da Família, em que os agentes comunitários de saúde atuavam, e os demais pontos da rede de apoio e proteção às populações LGBT. Onze dos participantes da pesquisa (ACS 2, 5, 6, 7 , 8, 9, 11, 12, 13, 14 e 15) não conheciam nenhum grupo social LGBT ou mesmo algum dispositivo de saúde, educação, assistência social ou cultura com o qual pudessem dialogar sobre as populações LGBT.

Uma das profissionais (ACS 4) afirmou saber da existência de alguns dispositivos com os quais poderia estabelecer contato, mas acabou colocando que a equipe à qual pertencia não mantinha um bom diálogo com eles. Apenas dois participantes (ACS 3 e 10) narraram ter um bom diálogo com outros pontos da rede com os quais pudessem tecer interfaces de cuidado no que diz respeito à saúde das populações LGBT.

Portanto, a garantia do acesso para assistência integral, quando analisada na perspectiva da rede de apoio LGBT, apresenta o profissional de saúde enquanto promotor das relações, como articulador em face dos conhecimentos, das tecnologias disponíveis e dos equipamentos sociais dos territórios. São, portanto, os fazeres dos ACS que podem se materializar em atos de saúde capazes de não patologizar, não desumanizar e nem estigmatizar, mas sim incluir e proteger ${ }^{2,7}$.

\section{Formação para trabalhar com as populações LGBT}

Por fim, durante as entrevistas com os agentes comunitários de saúde, debateu-se sobre a formação profissional que os mesmos pudessem ter recebido para lidar com as questões concernentes às populações LGBT. Entretanto, a maioria dos profissionais $(1,2,7,8,9,10,11,12,14$ e 15), segundo relato dos mesmos, não teve qualquer tipo de contato com essas discussões, seja por parte das secretarias de saúde, ou por iniciativa própria.

Do total de profissionais entrevistados, apenas dois deles (6 e 13) haviam passado por algum tipo de treinamento sobre a temática; entretanto, isso havia acontecido em virtude de um desejo particular e não por iniciativa de algum órgão de saúde. 
O ACS, na qualidade de educador, deve conhecer a realidade na qual está inserida a comunidade e por isso deve construir junto com ela processos de cuidado territorial e integral. O vínculo estabelecido entre esses profissionais e a população surge em face dessa proximidade e do contato pleno de afetividade desenvolvido ao logo da assistência oferecida ${ }^{13}$.

Estudos ${ }^{7,17}$ problematizam acerca da importância dos ACS diante das diversas funções desempenhadas, apontando que é fundamental que tenham um conhecimento e uma visão abrangente dos territórios de atuação, o que remete novamente à necessidade do trabalho contínuo em equipe, adquirindo saberes diversos e interdisciplinares. No entanto, a partir dos depoimentos dos entrevistados, fica claro uma insuficiência de habilidades e qualificações para lidar com as populações LGBT, uma vez que a prática profissional ainda é sustentada pelo senso comum. O que implica dizer que os saberes existentes geralmente são voltados apenas à técnica e aos procedimentos, desconsiderando aspectos sociais, culturais e políticos concernentes aos processos de saúde-adoecimento-cuidado das comunidades em que atuam.

\section{Considerações finais}

A partir de todos os elementos discutidos no decorrer do estudo, foi possível perceber o quanto as questões relativas à saúde das populações LGBT ainda são bastante negligenciadas no cotidiano de trabalho das equipes da Estratégia Saúde da Família. Prova disso são as narrativas dos agentes comunitários de saúde participantes, que atestam, ora uma generalização com as especificidades de cuidado, ora um desconhecimento diante de tais questões. Com o intuito de dirimir esses gargalos identificados, mecanismos de formação continuada (cursos, qualificações, seminários, simpósios, congressos, extensões, pesquisas, ligas acadêmicas, encontros de imersão etc.) podem ser sugeridos para os diferentes profissionais do campo da saúde, a fim de promover e fortalecer os diálogos sobre a saúde das populações LGBT.

Cabe destacar que o Ministério da Saúde lançou, em 2015, o curso online e gratuito sobre a saúde LGBT, desenvolvido de forma intersetorial com parcerias entre as Secretarias de Gestão Estratégica e Participativa (SGEP), Secretaria de Gestão do Trabalho e Educação na Saúde (SGETS), Universidade Aberta do Sistema Único de Saúde (UNA-SUS), Universidade do Estado do Rio de Janeiro (Uerj), e ainda com a colaboração do Comitê Técnico de Saúde LGBT. O curso já está em sua quarta edição e pode ser uma alternativa de capacitação profissional para todos aqueles que compõem o SUS.

Apostamos na formação de qualidade para o SUS como um caminho potente e desafiador para proporcionar uma mudança de paradigmas na atuação profissional das equipes da Estratégia Saúde da Família, de modo que estas passem a agregar, em seu cotidiano de trabalho, os aspectos sociais, econômicos e políticos que se inscrevem na dinâmica de saúde das populações LGBT.

O estudo aponta uma realidade brasileira, especialmente no nordeste do país, o que limita algumas generalizações dos achados. Contudo, não se espera que resultados diferentes aos identificados pela localidade estejam presentes na cultura de outros serviços de saúde do Brasil.

\section{Referências}

1. Foucault M. História da sexualidade I: a vontade de saber. 5. ed. Rio de Janeiro: Paz e Terra; 2017.

2. Popadiuk GS, Oliveira DC, Signorelli MC. A Política Nacional de Saúde Integral de Lésbicas, Gays, Bissexuais e Transgêneros (LGBT) e o acesso ao processo transexualizador no Sistema Único de Saúde (SUS): avanços e desafios. Ci saúde colet [Internet]. Fev. 2017 [citado em 5 jan. 2019]; 22(5):1509-20. Disponível em: http://www.scielo.br/pdf/csc/v22n5/1413-8123-csc-22-05-1509.pdf.

3. Aguião S, Vianna A, Gutterres A. Limites, espaços e estratégias de participação do movimento LGBT nas políticas governamentais. In: Lopes JSL, Heredia B, organizadores. Movimentos sociais e esfera pública: burocracias, confrontos, aprendizados inesperados. Rio de Janeiro: CBAE; 2014. 
4. Cardoso MR, Ferro LF. Saúde e população LGBT: demandas e especificidades em questão. Psicol. cienc. prof. [Internet]. Ago. 2012 [citado em 12 jan. 2019]; 32(3):552-63. Disponível em: http://dx.doi. org/10.1590/S1414-98932012000300003.

5. Ministério da Saúde (BR), Secretaria de Gestão Estratégica e Participativa, Departamento de Apoio à Gestão Participativa. Política Nacional de Saúde Integral de Lésbicas, Gays, Bissexuais, Travestis e Transexuais. Brasília: Ministério da Saúde; 2013.

6. Ministério da Saúde (BR), Secretaria de Atenção à Saúde. Departamento de Atenção Básica. Política Nacional de Atenção Básica. Brasília: Ministério da Saúde; 2017.

7. Guimarães RCP, Cavadinha ET, Mendonça AVM, Sousa MF. Assistência à saúde da população LGBT em uma capital brasileira: o que dizem os agentes comunitários de saúde? Tempus Actas Saúde Colet [Internet]. Jul. 2017 [citado em dez. 2018];11(1):121-39. Disponível em: http://dx.doi.org/10.18569/ tempus.v11i1.2327.

8. Secretaria de Direitos Humanos da Presidência da República (BR). Relatório sobre violência homofóbica no Brasil: ano de 2014. Brasília: Secretaria de Direitos Humanos; 2014.

9. Gomes R. Análise e interpretação de dados de pesquisa qualitativa. In: Minayo MCS, Deslandes SF, Gomes R, organizadores. Pesquisa social: teoria, método e criatividade. Petrópolis: Vozes; 2016. p. 73-94.

10. Ministério da Saúde (BR), Secretaria de Gestão estratégica e Participativa, Departamento de Apoio à Gestão Participativa. Análise do acesso e da qualidade da atenção integral à saúde da população LGBT no SUS. Brasília: Ministério da Saúde; 2014.

11. Albuquerque GA, Garcia CL, Quirino GS, Alves MJA, Belém JM, Figueiredo FWS, et al. Access to health services by lesbian, gay, bisexual, and transgender persons: systematic literature review. BMC Int Health Hum Rights [Internet]. 2016 Jan. [cited feb. 2018];16(2):1-10. Disponível em: https://www.ncbi.nlm. nih.gov/pmc/articles/PMC4714514/.

12. Ferreira BO, Pedrosa JIS, Nascimento EF. Diversidade de Gênero e Acesso ao Sistema Único de Saúde. Rev. Bras. Promoç. Saúde [Internet]. Ago. 2017 [citado em mar. 2018];31(1):1-10. Disponível em: http://periodicos.unifor.br/RBPS/article/view/6726/pdf.

13. Costa SM, Araújo FF, Martins LV, Nobre LLR, Araújo FM, Rodrigues CAQ. Agente comunitário de saúde: elemento nuclear das ações em saúde. Ci Saúde Colet [Internet]. Dez. 2013 [citado em jan. 2019];18(7):2147-56. Disponível em: http://www.scielo.br/scielo.php?pid=S1413$\underline{81232013000700030 \& \text { script }=\text { sci abstract\&tlng }=\text { pt. }}$.

14. Melo EA, Maksud I, Agostini R. Cuidado, HIV/Aids e atenção primária no Brasil: desafio para a atenção no Sistema Único de Saúde? Rev Panam Salud Publica [Internet]. Dez. 2018. [citado em jan. 2019];42:e151. Disponível em: https://doi.org/10.26633/RPSP.2018.151.

15. Lionço T. Que direito à saúde para a população GLBT? Considerando direitos humanos, sexuais e reprodutivos em busca da integralidade e da equidade. Saude soc [Internet]. Dez. 2008 [citado em jan. 2019];17(2):11-21. Disponível em: http://www.scielo.br/pdf/sausoc/v17n2/03.pdf.

16. Coelho LM. A representação social da homossexualidade feminina nos ginecologistas do ponto de vista das mulheres lésbicas e bissexuais. Rev Tesseract [Internet]. Jul. 2001 [citado em ago. 2018];4(3). Disponível em: http://tesseract.sites.uol.com.br/textoleilacoelho.htm.

17. Santos AR, Santos RMM, Souza ML, Boery RNSO, Sena ELS, Yarid SD. Implicações bioéticas no atendimento de saúde ao público LGBTT. Rev Bioét. [Internet]. Dez. 2015 [citado em 5 dez. 2018];23(2):400-8. Disponível em: http://www.scielo.br/scielo.php script=sci arttext\&pid=S1983$\underline{80422015000200400 \& \operatorname{lng}=\mathrm{pt} \text {. }}$

18. Bittencourt D, Fonseca V, Segundo M. Acesso da população LGBT moradora de favelas aos serviços públicos de saúde: entraves, silêncios e perspectivas. Conexões Psi [Internet]. 2014 Jan [citado em jan. 2019];2(2):60-85. Disponível em: http://apl.unisuam.edu.br/revistas/index.php/ conexoespsi/article/ view/542/504.

19. Paim JS. Sistema Único de Saúde (SUS) aos 30 anos. Ciênc. saúde coletiva [Internet]. Ago. 2018 [citado em jan. 2019];23(6):1723-28. Disponível em: http://dx.doi.org/10.1590/1413-81232018236.09172018.

20. Lemos A. Direitos sexuais e reprodutivos: percepção dos profissionais da atenção primária em saúde. Saúde debate [Internet]. Ago. 2014 [citado em jan. 2019];38(101):244-53. Disponível em: http://www. scielo.br/pdf/sdeb/v38n101/0103-1104-sdeb-38-101-0244.pdf. 